\title{
PMMA-SiO ${ }_{2}$ Organic-Inorganic Hybrid Coating Application to Ti-6Al-4V Alloy Prepared through the Sol-Gel Method
}

\author{
Joseane A. Santana, ${ }^{a}$ Sandra R. Kunst, ${ }^{b}$ Cláudia T. Oliveira, ${ }^{b}$ Antonio A. Bastos, ${ }^{c}$ \\ Mario G. S. Ferreira ${ }^{\circledR c}$ and Victor H. V. Sarmento ${ }^{\circledR} * a$ \\ ${ }^{a}$ Departamento de Química, Universidade Federal de Sergipe, Campus Professor Alberto Carvalho, \\ Av. Vereador Olímpio Grande s/n, 49500-000 Itabaiana-SE, Brazil \\ ${ }^{b}$ Instituto de Ciências Criativas e Tecnológicas (ICCT), Universidade Feevale, \\ 93510-250 Novo Hamburgo-RS, Brazil \\ ${ }^{c}$ Department of Materials and Ceramic Engineering (DEMaC), \\ Aveiro Institute of Materials (CICECO), University of Aveiro, 3810-193 Aveiro, Portugal
}

\begin{abstract}
Siloxane-poly(methyl methacrylate) (PMMA) hybrid was synthesized based on the sol-gel method and applied to Ti-6Al-4V through dip-coating. The structural feature of the hybrid was subjected to Fourier-transform infrared spectroscopy (FTIR) and thermogravimetric analysis (TG); its morphological properties were analyzed through scanning electron microscope (SEM), energy dispersive spectrometry (EDS), atomic force microscopy (AFM) and contact angle. The electrochemical behavior and corrosion resistance of both the hybrid coating and the uncoated substrate were investigated based on electrochemical impedance spectroscopy (EIS) and scanning vibrating electrode technique (SVET). Results showed homogeneous coating formation due to the rigid hybrid network formed during polymerization, hydrolysis and condensation reactions. This outcome suggested interaction between the organic (methyl methacrylate (MMA)) and inorganic (tetraethyl orthosilicate (TEOS)) phases, which was favored by the coupling agent (3-(trimethoxysilyl)propyl methacrylate (TMSM)). The S0M (PMMA-SiO 2 hybrid Ti-6Al-4V coated alloy) film presented regular topography and adherence to the substrate. Electrochemical simulated body fluid (SBF) tests showed that the hybrid coating presented better barrier properties ( $168 \mathrm{~h}$ of the immersion time) than the uncoated substrate, fact that makes it an interesting material for anti-corrosive applications in biomaterials.
\end{abstract}

Keywords: implants, biomaterials, hybrids, sol-gel, corrosion

\section{Introduction}

Ti-6Al-4V alloys have been the most used metal biomaterials in the last decades, mainly for orthopaedic and dental applications. They have excellent corrosion resistance, high static and fatigue strength, relatively-low elastic modulus, low weight ratio, high biocompatibility and direct bone apposition. ${ }^{1-3}$

However, some factors limit the use of alloys in biomedical applications; among them, one finds fibrous tissue formation at the bone/implant interface; ${ }^{2,3} \mathrm{Al}$ and $\mathrm{V}$ ion release, which can cause adverse reactions in tissues and lead to neurological disorders; ${ }^{4,5}$ as well as corrosion and mechanical wear associated with implantation time. ${ }^{6}$

*e-mail: vhsarmento@ufs.br
Several strategies such as surface passivation, electrochemical polishing, paints, sol-gel, ${ }^{7}$ physical vapor deposition (PVD) and polymer-derived ceramic coatings ${ }^{8}$ can be adopted to repair early implant failures. Among them, sol-gel processes can be a potential alternative to increase the bioactivity and biocompatibility degree of implanted metal surfaces. ${ }^{9,10}$

The sol-gel process uses a versatile synthesis method to produce new materials, whereas the chemistry of this process is based on hydrolysis and on condensation reactions of metal alkoxides; ${ }^{11}$ besides, it allows controlling both the chemistry and the molecular level of the structure when synthesis parameters, such as the amount of precursors, solvents, catalyst and processing temperatures, change. The remarkable advantages of sol-gel processing allow the production of organic-inorganic hybrid coatings ${ }^{12}$ 
Table 1. Chemical composition of the Ti-6Al-4V alloy ${ }^{18}$

\begin{tabular}{cccccccccc}
\hline & Al & V & C & Fe & O & Ti & H & & \\
\hline Composition / wt.\% & $5.5-6.5$ & $3.5-4.5$ & $\leq 0.08$ & $\leq 0.25$ & $\leq 0.13$ & $\leq 0.05$ & $\leq 0.012$ & $88.50-90.50$ \\
\hline
\end{tabular}

that combine the hydrophobicity and flexibility of organic coatings to the mechanical strength and hardness of the inorganic ones.

Organic-inorganic siloxane-poly(methyl methacrylate) hybrids (PMMA- $\mathrm{SiO}_{2}$ ) are a class of materials developed through the sol-gel method and widely applied in different scientific fields. ${ }^{11-13}$ The bioactivity of these hybrid systems is assured when they are used as bone cement ${ }^{14}$ and bioglass ${ }^{15}$ in bone reconstruction processes. Studies have indicated that chemical interactions between the organic and inorganic phases generate materials with better bone replacement applications than systems based on pure PMMA polymer. Nowadays, $\mathrm{PMMA}-\mathrm{SiO}_{2}$ coatings are extensively used for corrosion resistance applications $;{ }^{16,17}$ however, there are not reports in the literature about the application of these coatings to Ti$6 \mathrm{Al}-4 \mathrm{~V}$ alloys. In addition, these systems are non-toxic, alkoxysilane-based coatings capable of enhancing the bioactivity of, and biocompatibility with, several metal substrates.

Therefore, the aim of the current study was to develop and investigate hybrid coatings based on precursors such as methyl methacrylate (MMA) and tetraethyl orthosilicate (TEOS), synthesized through the sol-gel method and applied to Ti-6Al-4V alloys through dip coating, by taking into consideration the corrosion resistance and bioactive features of these coatings.

\section{Experimental}

\section{Materials and methods}

\section{Chemicals}

Chemical substances such as 3-(trimethoxysilyl)propyl methacrylate (TMSM, 98\%, Sigma-Aldrich, Madrid, Spain), benzoyl peroxide (BPO, 75\%, Vetec, Duque de Caxias, Brazil), hydrochloric acid ( $\mathrm{HCl}$, Merck, Dortmund, Germany), tetraethyl orthosilicate (TEOS, Sigma-Aldrich, Madrid, Spain) and deionized water were used in the experiment. Methyl methacrylate (MMA, 98\%, Neon, Suzano, Brazil) was distilled under atmospheric pressure for hydroquinone (polymerization inhibitor) removal purposes. Tetrahydrofuran (THF, 99.70\%, Neon, Suzano, Brazil) was dried on sodium sulfate $\left(\mathrm{Na}_{2} \mathrm{SO}_{4}, 99 \%\right.$, Neon, Suzano, Brazil).

\section{Ti-6Al-4V alloy}

The herein used Ti-6Al-4V alloy came in the form of a 0.15 mm-thick sheet (TiBrasil, Titanium, Butantã, Brazil). Table 1 presents the chemical composition of the alloy used for surgical implant purposes, as described by the American Society for Testing and Materials (ASTM F136). ${ }^{18}$

\section{Preparation of the inorganic-organic hybrid}

The procedure adopted to synthesize the siloxanePMMA hybrid followed two steps and was based on the sol-gel process. The first step comprised the copolymerization of MMA and TMSM (organic phase), whereas the second one consisted in preparing the inorganic phase based on TEOS, $\mathrm{HCl}$ and deionized water. Hybrid formation resulted from the mixture of both phases in order to generate a homogeneous sol. ${ }^{15,16,19,20}$

\section{Synthesis of $\mathrm{p}$ (MMA-co-TMSM) copolymer}

The 0.1 TMSM:MMA molar ratio was used to synthesize the copolymer; $0.037 \mathrm{~mol}$ of TMSM, $0.37 \mathrm{~mol}$ of MMA, $0.0002 \mathrm{~mol}$ of BPO and $45 \mathrm{~mL}$ of THF (solvent) were added to a three-neck round-bottom flask. The reaction mixture was refluxed at $68{ }^{\circ} \mathrm{C}$ for $3 \mathrm{~h} .{ }^{21}$ The resulting solution was stored in freezer for further use.

\section{Hybrid sol synthesis}

The hybrid sol resulted from the mixture at copolymer:inorganic phase volumetric ratio $60: 40 .{ }^{15}$ The inorganic phase derived from the mixture of TEOS, deionized water and $\mathrm{HCl}$ at TEOS: $\mathrm{H}_{2} \mathrm{O}: \mathrm{HCl}$ molar ratio 1:8:0.01; it was stirred for $30 \mathrm{~min}$ and added with copolymer solution until complete homogenization. The reaction mixture was transferred to a three-neck roundbottom flask and subjected to reflux at $60{ }^{\circ} \mathrm{C}$ for $30 \mathrm{~min}$ in order to generate a transparent hybrid sol. Finally, the hybrid sol was stored in Eppendorf tube at $80{ }^{\circ} \mathrm{C}$, for $24 \mathrm{~h}$, to enable total system gelation for later structural characterization (Fourier transform infrared spectroscopy (FTIR)) and thermal (thermogravimetric (TG)) analysis.

\section{Substrate preparation and film deposition}

Metal substrates were cut into $20 \times 20 \mathrm{~mm}$ pieces, polished with 1000-grit silicon carbide sandpaper, degreased with neutral detergent and washed with acetone. Next, they were subjected to acid pre-treatment with $\mathrm{HCl}\left(1 \mathrm{~mol} \mathrm{~L}^{-1}\right)$ solution for $30 \mathrm{~s}$ at room temperature and thoroughly rinsed 
with distilled water. After these procedures were over, the film was deposited through dip-coating (Marconi, model MA765). The substrate was immersed in hybrid sol for $300 \mathrm{~s}$ and withdrawn at hoisting speed $14 \mathrm{~cm} \mathrm{~min}^{-1}$ to enable monolayer formation. The resultant coated sample was dried at $60{ }^{\circ} \mathrm{C}$ for $24 \mathrm{~h}$ and cured at $160{ }^{\circ} \mathrm{C}$ for $3 \mathrm{~h} .{ }^{19}$ The surface-treated alloy was named TWC (Ti-6Al-4V without coating), whereas the hybrid coating was named SOM (PMMA-SiO 2 hybrid Ti-6Al-4V coated alloy).

\section{Structural analysis}

FTIR spectroscopy was adopted to the analysis of hybrid's chemical structure. FTIR spectra were obtained in IR Prestige-21 spectrometer (Shimadzu), which was operated at transmittance mode at the range 4000 to $400 \mathrm{~cm}^{-1}$ and $4 \mathrm{~cm}^{-1}$ resolution.

Hybrid's thermal behavior was analyzed through thermogravimetry (TG). The TG curve was generated in TGA Q50 thermobalance (TA Instruments) under dynamic argon atmosphere at flow and heating rates of $60 \mathrm{~mL} \mathrm{~min}^{-1}$ and $5{ }^{\circ} \mathrm{C} \mathrm{min}^{-1}$ (from room temperature to $600{ }^{\circ} \mathrm{C}$ ), respectively. The analysis was applied to approximately $7 \mathrm{mg}$ of powder sample in platinum pan. Derivative thermogravimetry (DTG) was used to accurately analyze the thermal events.

\section{Surface characterization}

The morphological characterization of uncoated and coated substrates was performed in Tescan MIRA3 field emission scanning electron microscope (FESEM), whereas the elemental map of the coated substrate was generated through energy dispersive spectrometry (EDS), by using the X-Max system of Oxford Instruments.

The water contact angles of the uncoated and coated metal substrates were measured based on the sessile drop method. The reported values were the mean of three measurements; data were acquired in the Surftens 4.5 software.

The adhesion of the SOM hybrid coating was investigated through standard tape test (ASTM D3359), ${ }^{22}$ which was performed over 7 vertical and 7 horizontal lines, which formed $1 \mathrm{~mm}$ squares. After $3 \mathrm{~min}$, the tape was rapidly removed, although the angle was kept as close as possible to $180^{\circ}$. Next, the coated metal substrate was analyzed in FESEM in order to evaluate whether there was, or not, detachment of the organosilane coating layer.

Atomic force microscopy (AFM) images were generated in Shimadzu SPM-9700 microscope, which was operated in the contact mode, with silicon nitride tips, at vertical scan capability of $8 \mu \mathrm{m}$ and scanning area of $10 \times 10 \mu \mathrm{m}$. Surface roughness evolution was analyzed through Ra measurements (arithmetical mean deviation of the profiles); analyses were carried out in the Image $\mathrm{J}$ software. $^{23}$

\section{Electrochemical characterization}

Electrochemical measurements were performed in METHROM Autolab (model PGSTAT 302N). Analyses were carried out in a conventional electrochemical cell composed of three electrodes; the saturated calomel electrode (SCE) was used as reference, whereas the platinum counter electrode, as well as the uncoated and coated metal substrates, were used as working electrode; the exposed surface area comprised $0.739 \mathrm{~cm}^{2}$.

The electrochemical tests used simulated biological fluid (SBF) solution as electrode at $37^{\circ} \mathrm{C}(\mathrm{pH} 7.41)$ in order to simulate body environment conditions. The solution was prepared in compliance with the protocol developed by Kokubo and Takadama. ${ }^{24}$

Electrochemical impedance spectroscopy (EIS) measurements were carried out at open-circuit potential, at frequency range from $100 \mathrm{kHz}$ to $10 \mathrm{mHz}$ (10 points per frequency decade) and sine wave perturbation amplitude of $10 \mathrm{mV}$ (rms). ${ }^{19}$ The uncoated and coated metal substrates were monitored for $168 \mathrm{~h}$ of immersion.

Scanning vibrating electrode technique (SVET) measurements were performed by Applicable Electronics Inc. (USA) and controlled in the ASET 2.00 software by ScienceWares (USA). The vibrating electrode was made of platinum-iridium alloy covered with a polymer of uncovered tip (10 $\mu$ m diameter). The electrode vibrated in two directions, i.e., parallel $(x)$ and perpendicular $(z)$ to the surface. Vibration frequencies in $x$ and $z$ were $162 \mathrm{~Hz}$, whereas vibration amplitudes had twice the diameter of the tip. SVET maps were obtained at mean distance $200 \mu \mathrm{m}$ from the surface of the substrates.

Pieces $(1 \times 1 \mathrm{~cm})$ of uncoated and coated metal substrates were glued to an epoxy sample holder $(3 \mathrm{~cm}$ diameter and approximately $1 \mathrm{~cm}$ height) for SVET measurement purposes. Substrates were isolated with a mixture of beeswax and colophony $(3: 1 \mathrm{~m} / \mathrm{m})$; only a window measuring a few $\mathrm{mm}^{2}$ was left to be exposed to the test solution (SBF). Scotch tape was applied around the epoxy cylinder to make a reservoir (ca. $6 \mathrm{~mL}$ ) to the solution.

Two systems were investigated based on SVET: the first one consisted in the immersion of substrates in SBF solution for $1 \mathrm{~h}$ at $37^{\circ} \mathrm{C}$, whereas the second one consisted in results obtained at applied potential of $-1.2 \mathrm{~V}$ for 1 and $168 \mathrm{~h}$ of immersion in SBF solution at $37{ }^{\circ} \mathrm{C}$. These measurements were conducted with CompactStat Ivium (The Netherlands) potentiostat, which was equipped with 
an electrochemical cell. Platinum wire was used as counter electrode (CE), whereas $\mathrm{Ag} / \mathrm{AgCl} / 0.05 \mathrm{M} \mathrm{NaCl}$ was used as reference electrode (RE). All the electrochemical tests were performed in triplicate and presented similar results.

\section{Results and Discussion}

\section{Structural analysis}

Figure 1 shows the result of the FTIR analysis applied to the powdered SOM hybrid sample. Band attributions characterizing $\mathrm{PMMA}-\mathrm{SiO}_{2}$ hybrid formation are also presented in this figure. A broad band centered at $3500 \mathrm{~cm}^{-1}$ and a shoulder located at $959 \mathrm{~cm}^{-1}$ were attributed to the axial deformation of silanol groups ( $\mathrm{Si}-\mathrm{OH})$; thus, this outcome indicates that the $\mathrm{Si}-\mathrm{OH}$ groups were not fully crosslinked after the condensation reaction. Kunst et al. ${ }^{25}$ also reported a broad band at approximately 3200 and $3700 \mathrm{~cm}^{-1}$ in the spectrum region after the silane coating was dried and attributed the deformations of $\mathrm{O}-\mathrm{H}$ bonds. ${ }^{19,25}$

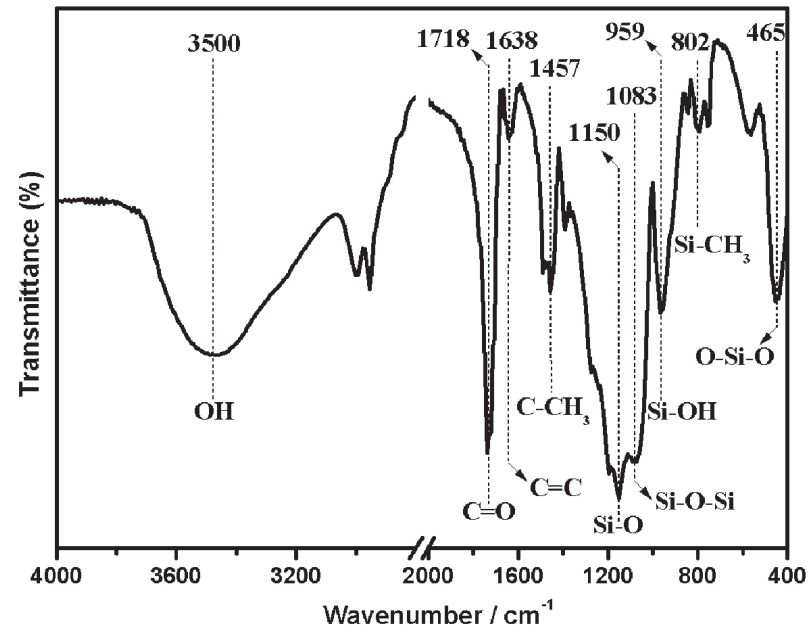

Figure 1. FTIR spectra (KBr) of the SOM sample.

Furthermore, more bands in regions corresponding to silicon bonds were observed between 1250 and $465 \mathrm{~cm}^{-1}$, at $1150 \mathrm{~cm}^{-1}$ ( $\mathrm{Si}-\mathrm{O}$ stretching), $1083 \mathrm{~cm}^{-1}(\mathrm{Si}-\mathrm{O}-\mathrm{Si}$ vibrations), $959 \mathrm{~cm}^{-1}$ ( $\mathrm{Si}-\mathrm{OH}$ vibrations), $802 \mathrm{~cm}^{-1}\left(\mathrm{Si}-\mathrm{CH}_{3}\right.$ vibrations) and $465 \mathrm{~cm}^{-1}$ (O-Si-O stretching). Si-O-Si groups found in the SOM hybrid sample indicated that hydrolysis and condensation reactions enabled structural crosslinking (covalent bonds and crosslinks). ${ }^{17,26,27}$

On the other hand, a band at $802 \mathrm{~cm}^{-1}$, which corresponded to $\mathrm{Si}-\mathrm{CH}_{3}$ vibrations, indicated that the hydrolysis of TEOS and TMSM precursors was not complete, since it is known that hydrolysis happens during the conversion of these groups into silanol groups ( $\mathrm{Si}-\mathrm{OH})$. The polymerization of methacrylate groups belonging to
TMSM and MMA was evidenced by the presence of bands at approximately 1345 and $1500 \mathrm{~cm}^{-1}$, which referred to the asymmetric and symmetric stretching of different kinds of $\mathrm{C}-\mathrm{H}$ bonds. ${ }^{28}$

The strong band at $1718 \mathrm{~cm}^{-1}$ was attributed to $\mathrm{C}=\mathrm{O}$ stretching vibrations in carbonyl groups found in both polymeric structures of the MMA/TMSM precursors, ${ }^{17,29}$ whereas a weak band at approximately $1638 \mathrm{~cm}^{-1}$ was attributed to $\mathrm{C}=\mathrm{C}$ bonds. These results indicated that PMMA had unsaturated end chains. In other words, the presence of these groups showed that the polymerization of the methacrylate group of MMA and TMSM was not complete. ${ }^{29}$ Therefore, this result indicates that the SOM hybrid sample has potential properties to be used as coating due to the presence of a silica network and of a highly-reticulated polymer.

Figure 2 presents the TG and DTG curves of the SOM hybrid sample. The thermal decomposition of the SOM hybrid can be associated with mass loss events reported by Kashiwagui et al..$^{30}$ for the neat PMMA, if one takes into consideration the large amount of polymers used in hybridsample composition. According to the literature, the thermal degradation of neat PMMA happens in three stages. The first thermal event presents temperature range from 100 to $200{ }^{\circ} \mathrm{C}$, and it is associated with the depolymerization of head-to-head linkages (less stable)..$^{29-31}$ The second thermal event takes place at temperature range from 250 to $300^{\circ} \mathrm{C}$, and it is associated with the degradation of unsaturated end chains. ${ }^{30,31}$ The third event, whose maximum depolymerization temperature is higher than $350{ }^{\circ} \mathrm{C}$, is attributed to random scissions of head-to-tail linkages. ${ }^{30,31}$

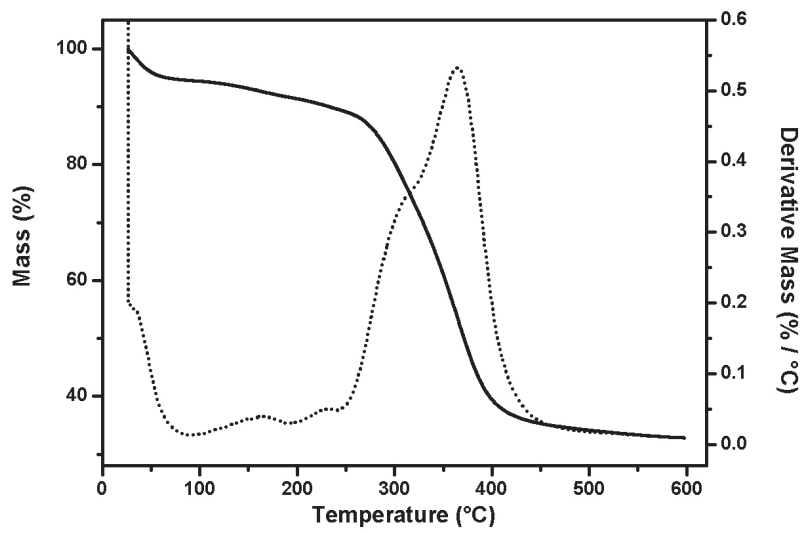

Figure 2. TG (solid line) and DTG (dotted line) curves generated for the SOM sample.

The SOM hybrid sample also presented three degradation stages, which were defined as head-to-head (from 100 to $250{ }^{\circ} \mathrm{C}$ ), terminal unsaturation (from 250 to $300{ }^{\circ} \mathrm{C}$ ) and head-to-tail (at approximately $365^{\circ} \mathrm{C}$ ). The presence of 
the alkoxide precursor (TEOS) in the composition of the sample shifted the degradation temperature of random scissions (third stage) to higher values; thus, such change was capable of improving thermal stability in comparison to neat PMMA. The presence of the second thermal degradation stage of the unsaturated end chain $(\mathrm{C}=\mathrm{C})$ was in compliance with the result recorded for FTIR spectra (Figure 1). ${ }^{29-31}$ Moreover, the initial hybrid mass loss at approximately $100{ }^{\circ} \mathrm{C}$ was associated with the removal of remaining solvent molecules (water and THF) and non-polymerized MMA monomers.

\section{Surface characterization}

Figure 3 shows SEM micrographs generated for uncoated (TWC) and hybrid coating (SOM) surfaces at magnitudes $250 \times$ and $1000 \times$. It is possible seeing differences in surface features of TWC (Figure 3a) and SOM samples (Figure $3 b$ ). The TWC sample presented several surface irregularities, which were attributed to the mechanical treatment with sandpaper and hydrochloric acid. This treatment allowed removing titanium oxides and surface impurities in order to enable the adhesion of the sol-gel film to be deposited. ${ }^{32,33}$ Surface irregularities were possibly caused during the pre-treatment, as reported by other authors ${ }^{34,35}$ in morphological studies conducted with Ti-6Al-4V alloys.

Based on Figure 3b, the SOM hybrid coating also presented some discontinuities caused by the treatment applied to the surface of the metal alloy, although in an amount smaller than the one recorded for the TWC sample. This outcome indicated that the hybrid coating coverage

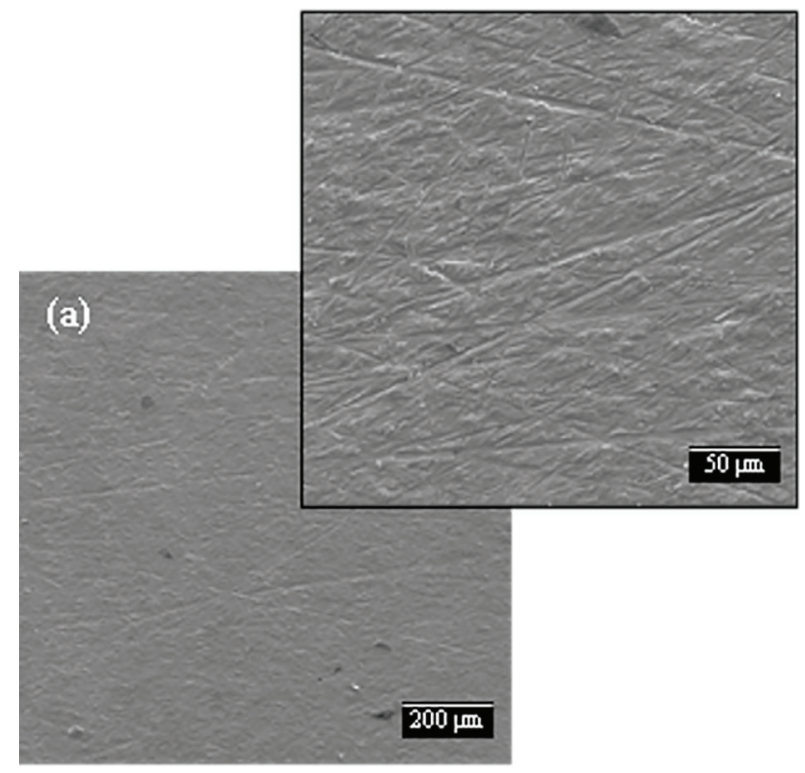

may have reduced surface irregularities. Similar results were reported by other researchers, ${ }^{34,36}$ who found that the pre-treatment applied to the surface of the metal alloy can favor the silane coating adhesion process.

Furthermore, the SOM coating (Figure $3 \mathrm{~b}$ ) also showed the formation of a layer with regular and homogeneous coverage. Early-deposited hybrid coatings set Van der Waals bonds with the metal surface, the so-called metaxilosane; then, stable covalent bonds $(\mathrm{Si}-\mathrm{O}-\mathrm{Si})$ were formed during the drying process and they enabled film adherence to the metal substrate. ${ }^{37}$ The presence of the organic component PMMA reduced coating porosity and the resulting film became more flexible and less susceptible to fractures during the drying process. ${ }^{17,19,37} \mathrm{It}$ was possible seeing some discontinuity in the SOM coating (indicated by blue arrows) since pre-treatment, ${ }^{11}$ as well as small clusters (white arrows) associated with different factors such as silicon agglomerates formed during the condensation process, and acrylate accumulation due to the coating cure process, when non-polymerized MMA species had volatilized and generated regions of stress and, consequently, caused coating flaws. ${ }^{38}$

Figure 4 shows SEM-EDS images of the SOM coating before (Figure 4a) and after (Figure 4b) the adhesion test, based on ASTM D 3359. ${ }^{22}$ According to the EDS mapping, the hybrid coating formed in the current study showed high titanium element ( $\mathrm{Ti}$ ) signal during the scanning procedure. This outcome indicated that the deposited hybrid coating had low thickness, fact that allowed the electron beam to overtake and detect the Ti-6Al-4V metal substrate. Similar results were reported by other researchers, ${ }^{10,39}$ who emphasized that the deposition of a single sol hybrid

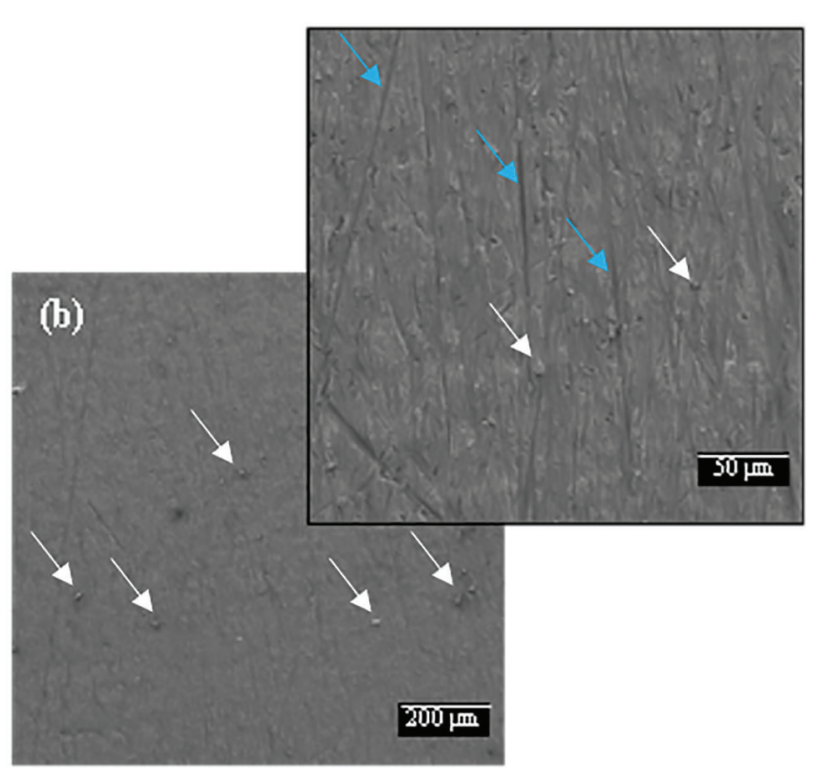

Figure 3. SEM images of (a) TWC and (b) SOM samples. 

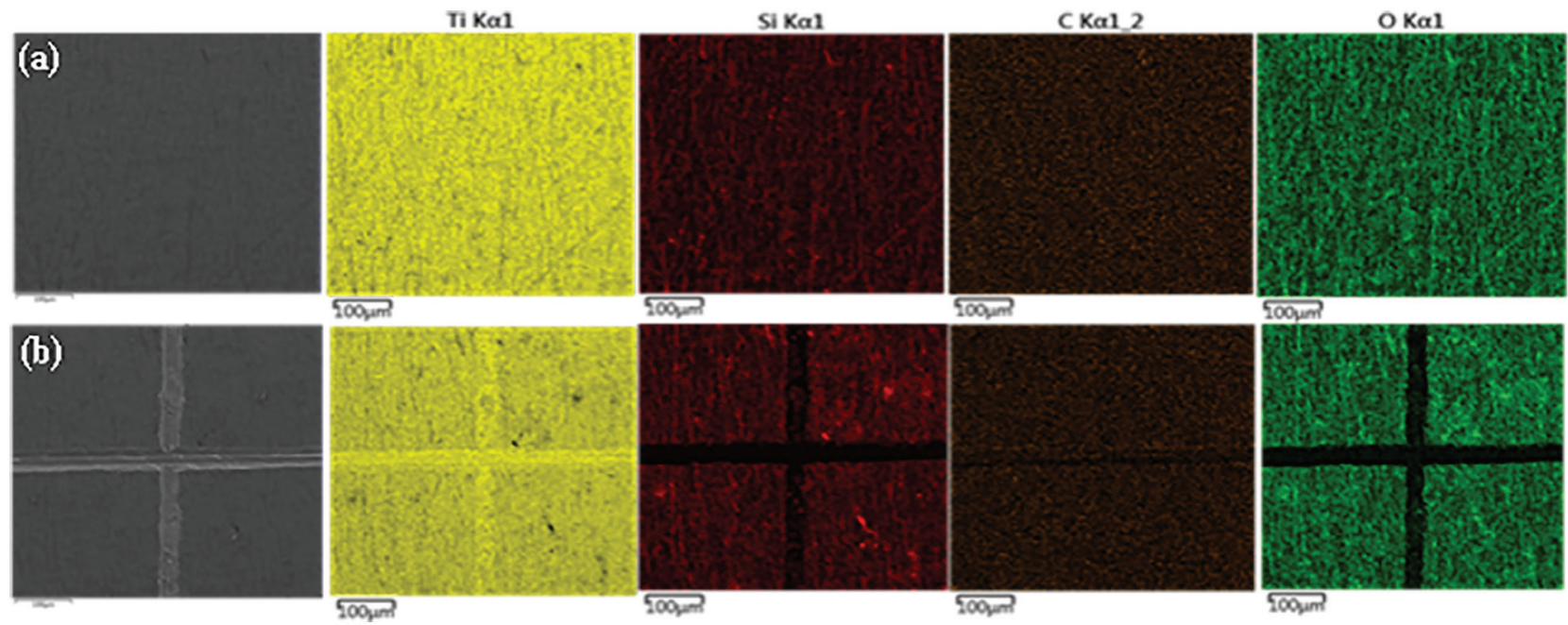

Figure 4. EDS mapping of SOM sample (a) before and (b) after the adhesion test.

layer on the surface of the Ti-6Al-4V alloy was enough to generate a flawless thin film with good protective properties.

Results in Figure 4a showed that silicon ( $\mathrm{Si}$ ), carbon (C) and oxygen (O) were evenly distributed throughout the SOM hybrid coating. The distribution of these elements confirmed the formation of the silicon network, as well as the polymerization of the organic phase, as seen in carbon distribution throughout the coating surface. The EDS mapping applied to Si (Figure 4a) showed small clusters with increased Si intensity signal in a few hybrid coating regions, and this outcome has confirmed the formation of silicon agglomerates during condensation reactions.

Figure $4 \mathrm{~b}$ shows that the intensity and homogeneity of $\mathrm{Si}, \mathrm{C}$ and $\mathrm{O}$ on the coating surface did not change after the adhesion test, since the coating remained well-adhered to the substrate, even after tearing. No coating flaking or peeling was observed in the immediate vicinity to the area where the incisions were made. These results corroborate studies available in the literature. ${ }^{40,41}$ Other researchers have observed the same behavior in PMMA-SiO 2 hybrid coatings; they attributed the good adhesion between films and substrates to the formation of metal-O-Si chemical bonds between the reactive functional groups of silane precursors and hydroxyl groups found on the surface of the substrates..$^{40,41}$

Wettability is an important surface property to be taken into consideration. Table 2 shows values and images of TWC and SOM surface wettability samples obtained after the contact angle (q), based on the sessile drop method. It is known that a given surface is hydrophilic if the surfacewater contact angle is narrower than $90^{\circ}$, whereas surfaces presenting contact angles wider than $90^{\circ}$ are hydrophobic.

According to Table 2, contact angle values recorded for TWC and SOM surfaces were significantly different.
Table 2. Contact angle values recorded for TWC and SOM samples

\begin{tabular}{l} 
Substrate $\begin{array}{c}\text { Standard deviation of the } \\
\text { contact angle / degree }\end{array}$ \\
\hline TWC \\
\hline \\
S0M \\
\hline
\end{tabular}

TWC: Ti-6Al-4V without coating; S0M: PMMA-SiO ${ }_{2}$ hybrid Ti-6Al-4V coated alloy.

Both surfaces were classified as hydrophilic, since they presented $\mathrm{q}<90^{\circ}$; however, the TWC uncoated surface was more hydrophilic than that of the SOM hybrid coating. The highest wettability value recorded for the TWC surface was attributed to the titanium oxide removal from the surface, fact that increased the free surface energy and surface roughness, in addition to enable a more hydrophilic surface. $^{32}$

Indeed, the deposition of the hybrid coating (SOM) reduced the wettability of the metal surface and made it more suitable for corrosion resistance applications. The formation of a well-crosslinked coating hindered the diffusion of potentially corrosive species at the coating/ metal interface. ${ }^{40}$ The hydrophobicity degree of the surface was directly associated with its corrosion resistance ability; this characteristic was proportional to the contact angle formed by sessile liquid drops on a coated metal surface. ${ }^{42}$

The higher contact angle value recorded for the SOM coating was attributed to the performance of the herein prepared hybrid coating, which protected it against 
corrosion due to the formation of a sufficient crosslinking physical barrier during polycondensation reactions. Hence, this coating presented contact angle of approximately $90^{\circ}$; consequently, it was less hydrophilic than the uncoated TWC surface. However, the immersion of the coated substrate in aqueous solution reduced this value, and this outcome indicated that $\mathrm{Si}-\mathrm{O}-\mathrm{Si}$ groups were not fully stable. Therefore, $\mathrm{Si}-\mathrm{O}-\mathrm{Si}$ groups can undergo hydrolysis reactions and form hydrophilic $\mathrm{Si}-\mathrm{OH}$ groups, to the extent that water and ions can penetrate, and react with, the coating/metal interface. ${ }^{43}$ Thus, silane films, even the most hydrophobic films, protect the metals. This process takes place because the adhesion and barrier properties of these films can change depending on the duration of their exposure to air or to aqueous solution, for $\mathrm{Si}-\mathrm{O}-\mathrm{Si}$ bonds are susceptible to undergo hydrolysis reactions. ${ }^{43,44}$

Despite differences in surface wettability values, it is known that the use of hybrid coating often increases the efficiency of the alloy barrier protection, since it reduces electrolyte permeation, as well as ions' leaching from the alloy to body environment. In addition, the hydrophilic nature of uncoated and coated surfaces make them favorable for cell adhesion processes. ${ }^{45}$ Studies have shown that large amounts of cells adhere to moderately hydrophilic surfaces such as SOM coating, whose composition includes a source of calcium. ${ }^{46}$

Moreover, surface roughness is another extremely important parameter to be investigated.

Figure 5 presents three-dimensional images of uncoated (TWC) and hybrid coating (SOM) surfaces, based on AFM analysis.

Based on Figure 5a, TWC presented irregular surface, whose defects resulted from surface treatments (mechanical treatment). Mean roughness (Ra) was $5.2 \mathrm{~nm}$; however, the Ra value of the surface significantly decreased (to $0.9 \mathrm{~nm}$ ) when the hybrid coating (Figure 5b) was deposited on the metallic surface.

(a) TWC

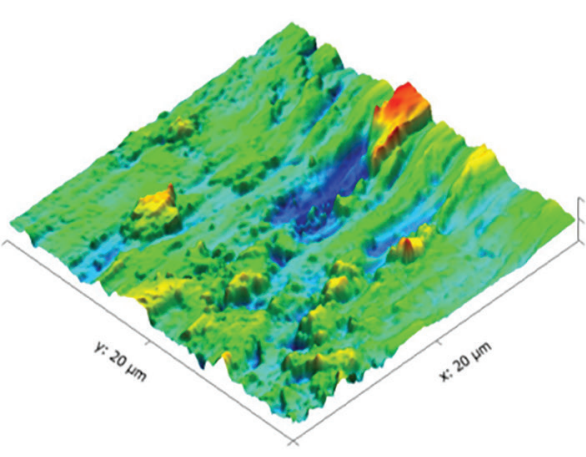

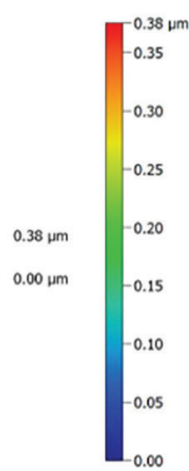

The SOM hybrid coating (Figure 5b) presented homogeneous and smooth topography; its mean roughness was approximately 5 times lower than that of the uncoated TWC surface. In addition, it presented only small discontinuities and some silicon agglomerates, as previously observed in the SEM assay. However, it presented higher regions, which were probably associated with the formation of acrylate aggregates (yellow spots), as well as of dark blue and light blue spots, which were attributed to different chemical compositions between these regions. $^{38}$

Moreover, defects on the surface of the SOM coating can be linked to the film formation process. Several factors may have contributed to such defects; among them, one finds irregular surface of the metal, formation of silicon agglomerates during the condensation process, as well as regions presenting different amounts of MMA. These phenomena can contribute to the generation of defective areas $;{ }^{45}$ in addition, the SOM coating provided good anchoring, coverage and uniformity to the metal substrate, and this process enabled surface leveling and made the metal substrate more homogeneous. ${ }^{32}$ According to roughness results recorded for the TWC and SOM surfaces, the coated surface was more suitable for corrosion resistance applications. It is known that lower roughness of surface improves the corrosion resistance.

According to investigations conducted by Ribeiro Filho et al. ${ }^{47}$ small decreases in surface Ra values can improve corrosion resistance. Studies available in the literature ${ }^{48}$ also reported that the electrochemical potential of metal implants changes depending on the roughness of the surface; therefore, implants presenting increased surface roughness make it difficult for electrons to be released and lead to lower electrochemical potential. ${ }^{48}$ However, topography is not the only factor responsible for improving corrosion resistance; this property is also influenced by surface oxide, deposits, coatings and surface area increase.

\section{(b) SOM}

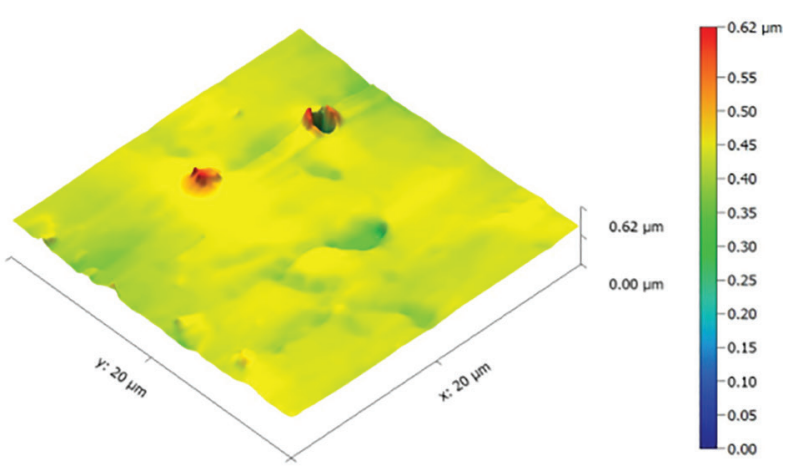

Figure 5. AFM results including topographic images of sample surfaces: (a) TWC and (b) SOM. 
Smooth surfaces do not have good biocompatibility to be seen as biomaterial, since the integration of implants to the bone tissue in vivo is associated with increased surface roughness in the implant. It happens because human osteoblasts adhere better to rough, than to smooth, surfaces. Thus, adhesion often increases on surfaces presenting mean roughness ( $\mathrm{Ra}$ ) from 1 to $2 \mu \mathrm{m} .{ }^{49,50}$

Therefore, the SOM hybrid coating was expected to improve implant biocompatibility and osseointegration, as well as to decrease the rejection rate, due to its low surface roughness. ${ }^{51}$ Thus, the coating was expected to present equilibrium between properties, as well as corrosion resistance and biocompatible characteristics.

\section{Corrosion analysis}

Figure 6 shows electrochemical impedance bode diagrams generated for the hybrid siloxane-PMMA coating (SOM) and for the uncoated substrate (TWC) immersed in SBF solution at $37^{\circ} \mathrm{C}$, for $1,24,72$, and $168 \mathrm{~h}$.

With respect to the TWC uncoated substrate (Figure 6a), a single phenomenon was observed in 1 and $168 \mathrm{~h}$ immersions in the medium at high frequency range. This outcome was attributed to the passive oxide formed on the surface of the substrate. The oxide response to medium

(a) TWC

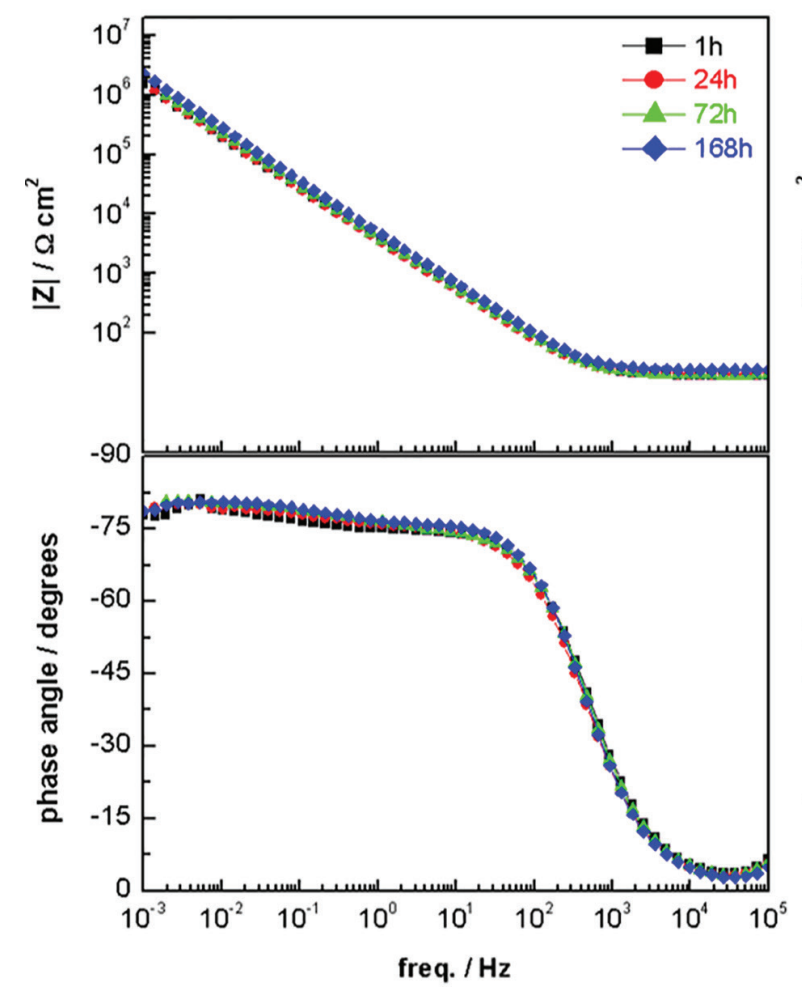

frequencies confirmed electrolyte permeability through the passive film, as well as its instability. ${ }^{52}$ As previously reported, assumingly, the simultaneous precipitation of aluminum, vanadium and titanium oxides was one of the causes the instability in the oxide formed on the Ti-6Al-4V alloy. This oxide complex on the surface of the Ti-6Al-4V alloy presented lower thermodynamic or kinetic stability than the $\mathrm{TiO}_{2}$ oxide formed in the bare metal. ${ }^{53}$

Based on thermodynamic characteristics involved in the oxide formation process, Heakal et al..$^{54}$ have emphasized that the presence of aluminum and vanadium on the surface of the substrate decreased the corrosion resistance and destroyed the characteristic passivation of the bare titanium bound to these elements, which was confirmed by electrochemical tests. ${ }^{34}$

The S0M hybrid coating (Figure 6b) recorded two phenomena for immersion times 1, 24, 72 and $168 \mathrm{~h}$ : (i) the first one, at medium-to-low frequency range, was attributed to changes in electrical conductivity during the exposure to the corrosive SBF environment; in other words, the electrolyte permeability through the film furthers the response of the passive film below the sol-gel coating: ${ }^{25}$ and (ii) the second one, at high frequency range, was associated with the presence of protective coating, which indicated high resistance. ${ }^{10,16}$

\section{(b) SOM}

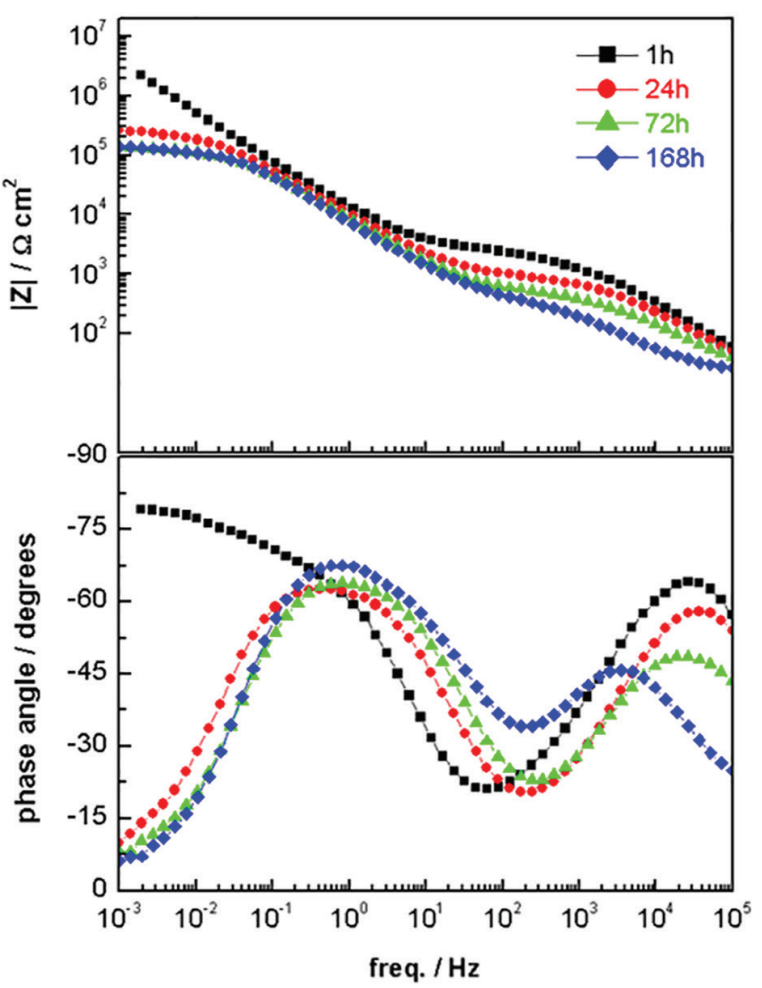

Figure 6. Bode diagrams generated for (a) uncoated substrate (TWC) and (b) hybrid siloxane-PMMA coating (S0M), after 1, 24, 72 and 168 h immersed in SBF solution at $37^{\circ} \mathrm{C}$. 
The good performance of the SOM coating was confirmed within the first hours of immersion in SBF solution, as show in Figure 6b. This protection was associated with the formation of $\mathrm{Si}-\mathrm{O}-\mathrm{Si}$ groups and of a dense network that hindered electrolytes' access to the metal and formed an effective diffusion barrier against corrosive attacks. ${ }^{34}$ These results are in compliance with data reported in SEM microscopy (Figure 3) and in contact angle-based assays (Table 2). The coating presented uniform characteristics and regular surface, which suggested improved chemical resistance and the physical barrier properties of the formed film.

Although the S0M coating showed good crosslinking, it was possible observing gradual decrease in the high frequency range phenomenon after 72 and $168 \mathrm{~h}$ of immersion; this outcome can be associated with electrolyte permeability through the film due to small discontinuities on the surface of the SOM coating. The presence of these discontinuities on the surface of the SOM coating was confirmed through SEM-EDS assays (Figure 4a).
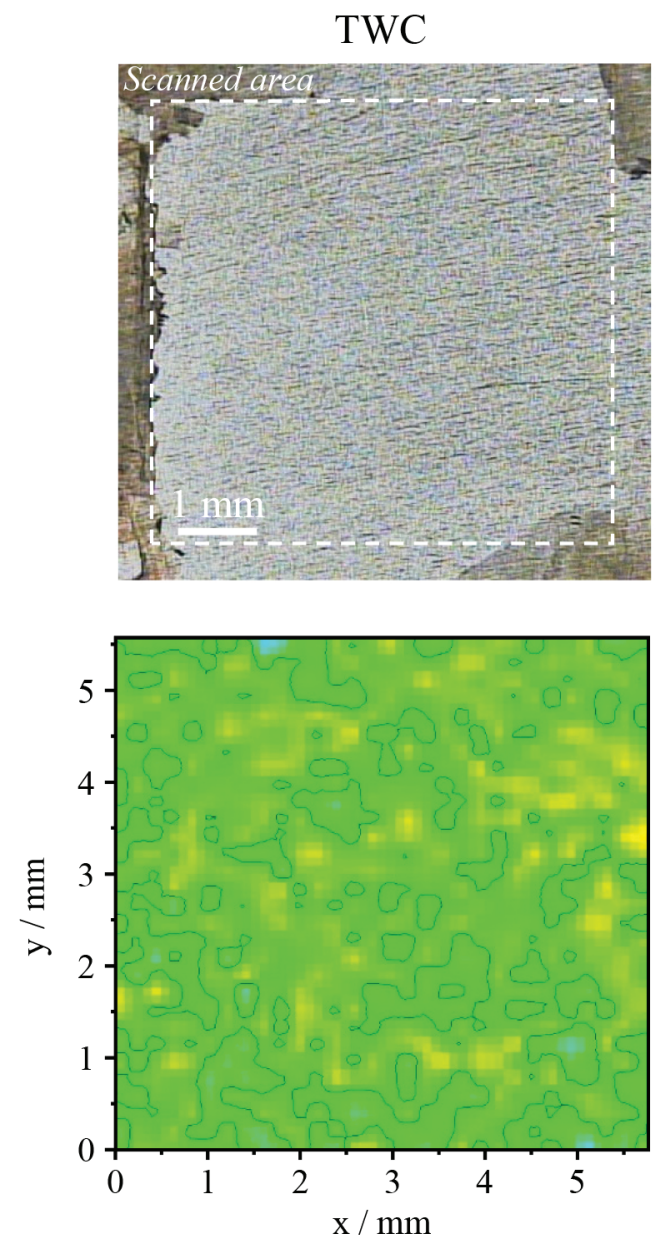

In addition, the SOM coating subjected to $168 \mathrm{~h}$ immersion presented lower impedance module at low frequencies than that observed in TWC. TWC did not show significant impedance variations, regardless of immersion time; this outcome was associated with oxide stability, which naturally grown on this sample. However, this oxide was removed from the Ti-6Al-4V alloy by means of chemical etching, before the deposition of the SOM hybrid coating, in order to enable the film to better adhere to the substrate. If one takes into consideration that the hybrid film permeates from $24 \mathrm{~h}$ of immersion on, the time constant observed at low frequencies refers to the TWC uncoated alloy, fact that indicates the lower performance of SOM.

Further information on the EIS assay can be obtained through complementary techniques such as the SVET, which provides the distribution and magnitude of anodic and cathodic activities in corrosive surface processes. ${ }^{55,56}$ Figure 7 shows SVET images and maps of the uncoated substrate (TWC) and hybrid siloxane-PMMA coating (S0M) immersed in SBF solution at $37^{\circ} \mathrm{C}$ for $168 \mathrm{~h}$. The
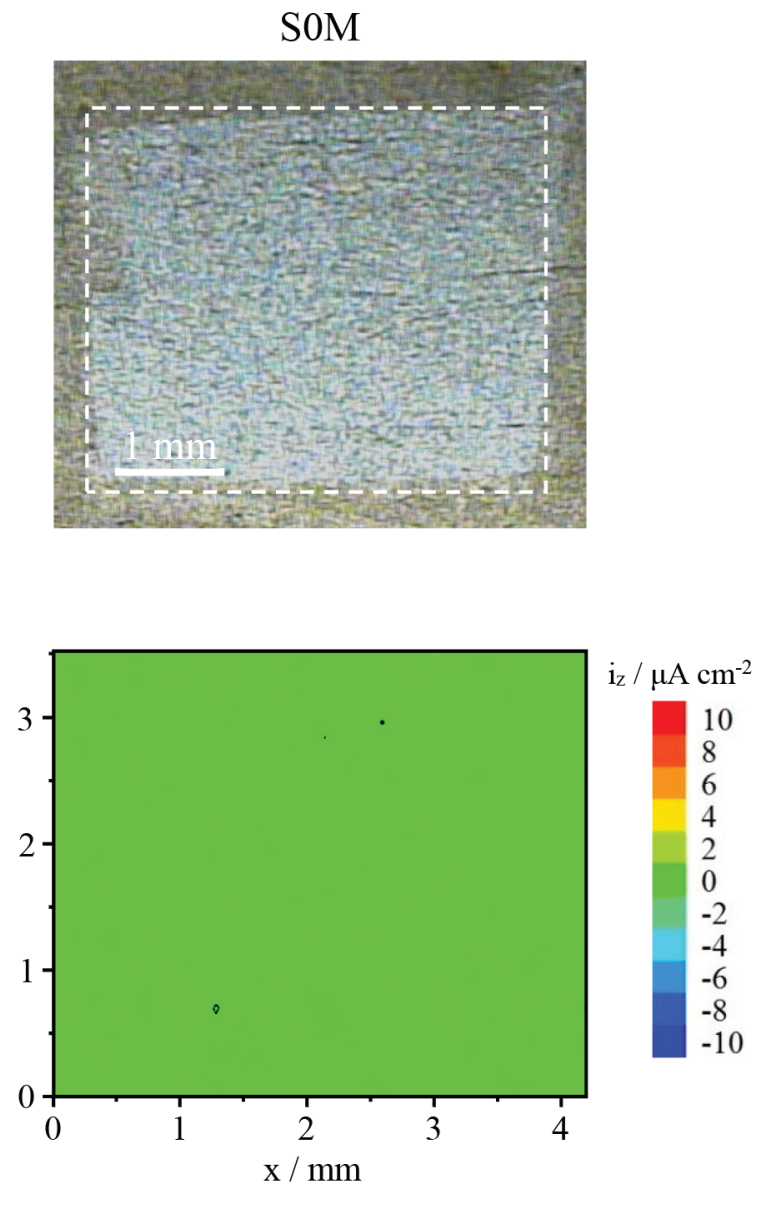

Figure 7. Optical pictures and SVET maps of the uncoated substrate (TWC) and hybrid siloxane-PMMA coating (S0M) after 168-h immersion in SBF at $37^{\circ} \mathrm{C}$. 

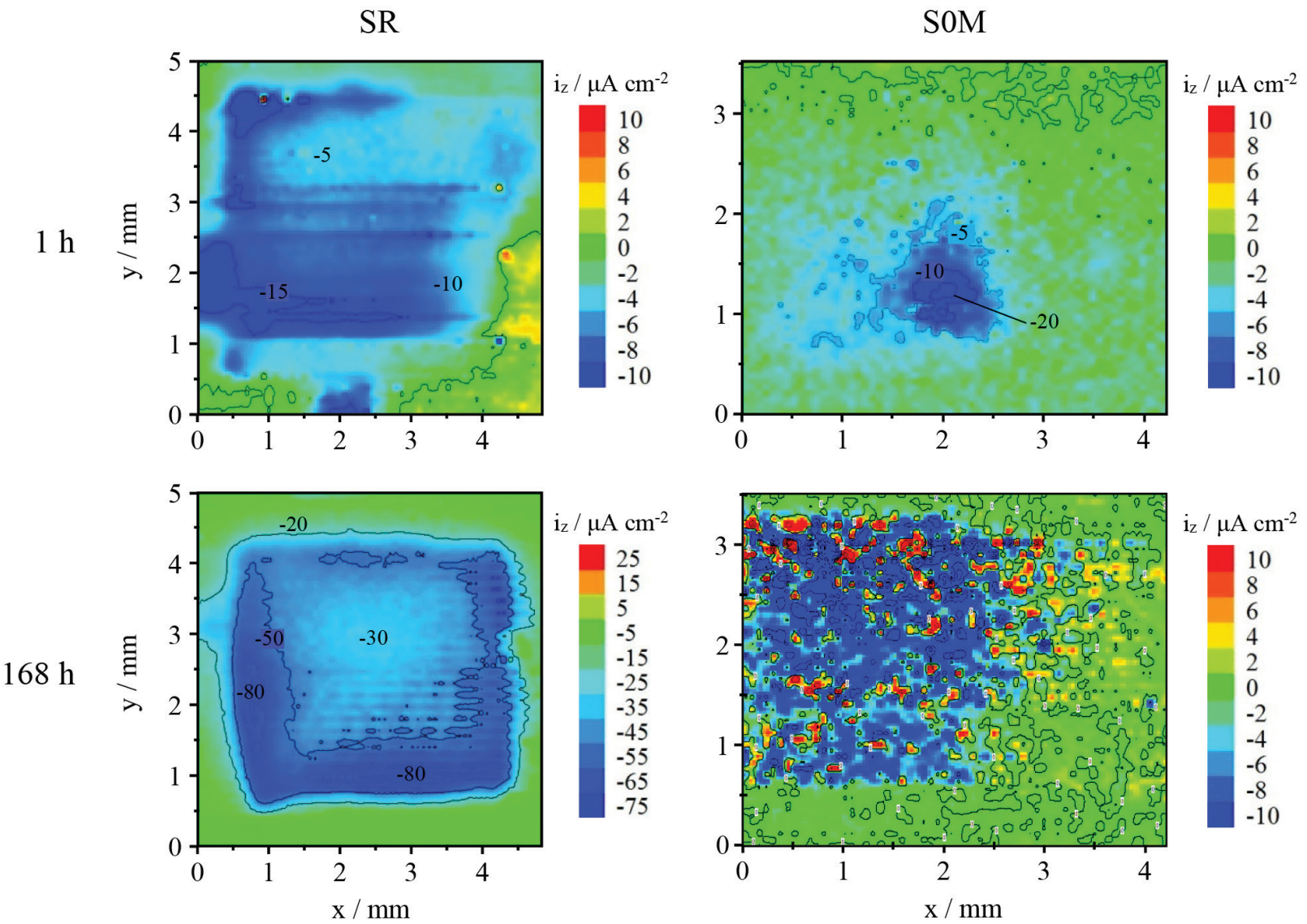

Figure 8. SVET maps measured during uncoated substrate (TWC) and hybrid siloxane-PMMA coating (S0M) polarization at potential of $-1.2 \mathrm{~V} v$. $\mathrm{Ag}|\mathrm{AgCl}| 0.05 \mathrm{M} \mathrm{NaCl}$, after 1 and $168 \mathrm{~h}$ of immersion in $\mathrm{SBF}$ at $37^{\circ} \mathrm{C}$.

images of the TWC and SOM surfaces indicated that, although they were immersed in biological corrosive environment, there was not pitting corrosion. The respective maps shown in Figure 8 indicate that it was not possible identifying instantaneous corrosion on the surface of the coatings, or any signs of corrosion, based on SVET. Both coatings presented green color throughout the surface area, which corresponds to zero current.

As previously mentioned, the biomedical Ti-6Al-4V alloy presented passive oxide layer on its surface; therefore, its corrosion rate was extremely slow, which made it impossible seeing corrosive processes in the surface maps where the blue color corresponds to negative currents (cathode), whereas the red color corresponds to positive currents (anode).

Figure 8 shows micrographs of SVET maps measured during uncoated substrate (TWC) and hybrid siloxanePMMA coating (SOM) polarization at potential of $-1.2 \mathrm{~V}$ vs. $\mathrm{Ag}|\mathrm{AgCl}| 0.05 \mathrm{M} \mathrm{NaCl}$, after 1 and $168 \mathrm{~h}$ of immersion in SBF at $37{ }^{\circ} \mathrm{C}$. At $-1.2 \mathrm{~V}$ vs. SCE the main cathodic reactions are the oxygen reduction reaction, $\mathrm{O}_{2(\mathrm{~g})}+2 \mathrm{H}_{2} \mathrm{O}_{(\mathrm{l})}+4 \mathrm{e}^{-} \rightarrow 4 \mathrm{OH}_{(\mathrm{aq})}$ and the reduction of water, $2 \mathrm{H}_{2} \mathrm{O}_{(\mathrm{l})}+2 \mathrm{e}^{-} \rightarrow \mathrm{H}_{2(\mathrm{~g})}+2 \mathrm{OH}_{(\mathrm{aq})}$. Both contribute to the current measured by SVET at the sol-gel defects exposing the underlying metal substrate.

Based on the results, the hybrid coating generated a protective layer on the TWC uncoated substrate; the greenish color (zero current) throughout the surface confirmed the efficiency of the deposited coating. The SOM coating presented only a few spots of anodic and cathodic activity in the central region of the map, fact that was attributed to discontinuities previously discussed in the morphological characterization section, based on SEM and EDS assays. On the other hand, the TWC uncoated substrate presented higher cathodic current intensity (blue color).

The cathodic current intensity considerably increased in both samples after $168 \mathrm{~h}$ immersion in biological solution; however, although the small discontinuities in the film enabled electrolyte diffusion in the SOM coating, results suggested that the coating remained adhered to the substrate, and such observation complies with data reported in the impedance tests.

\section{Conclusions}

The synthesis method was efficient in developing the 
$\mathrm{SiO}_{2}$-PMMA hybrid coating. The soft conditions of the sol-gel preparation process allowed generating a regular coating capable of adhering to the metal substrate.

Structural results (FTIR and TG) have evidenced that the SOM coating presented a rigid hybrid network, which was formed by covalent bonds and provided good thermal and morphological properties to the material. Morphological tests such as SEM, EDS, contact angle and AFM allowed evaluating and classifying the produced coating as thin, homogeneous, with regular topography and some discontinuities resulting from the condensation process and from the pre-treatment applied to the alloy.

The electrochemical experiments (EIS and SVET) have shown that the SOM hybrid coating generated a higher corrosion protection barrier than that of the uncoated TWC substrate, when it was exposed to body fluid at $37^{\circ} \mathrm{C}$. Based on electrochemical tests, the SOM hybrid coating protected the substrate even after $168 \mathrm{~h}$ immersion in corrosive medium.

Efficient polymerization, hydrolysis and condensation reactions produced a protective coating, which behaved as physical barrier between the substrate and the electrolyte; therefore, this coating is suitable for corrosion resistance and to be used in biomaterial applications.

\section{Acknowledgments}

The authors would like to thank CAPES (the Brazilian National Council for the Improvement of Higher Education). The current study was partly financed by Coordenação de Aperfeiçoamento de Pessoal de Nível Superior, Brasil (CAPES), Finance Code 001.

\section{References}

1. Niinomi, M.; J. Mech. Behav. Biomed. Mater. 2008, 1, 30.

2. Nelea, V.; Morosanu, C.; Iliescu, M.; Mihailescu, I. N.; Surf. Coat. Technol. 2003, 173, 315.

3. Koch, C. F.; Johnson, S.; Kumar, D.; Jelinek, M.; Chrisey, D. B.; Doraiswamy, A.; Jin, C.; Narayan, R. J.; Mihailescu, I. N.; Mater. Sci. Eng., C 2007, 27, 484.

4. Jacobs, J. J.; Silverton, C.; Hallab, N. J.; Skipor, A. K.; Patterson, L.; Black, J.; Galante, J. O.; Clin. Orthop. Relat. Res. 1999, 358, 173.

5. Manam, N. S.; Harun, W. S. W.; Shri, D. N. A.; Ghani, S. A. C.; Kurniawan, T.; Ismail, M. H.; Ibrahim, M. H. I.; J. Alloys Compd. 2017, 701, 698.

6. Tsipas, S. A.; Gordo, E.; Jiménez-Morales, A.; Corros. Sci. 2014, 88, 263.

7. Catauro, M.; Bollino, F.; Papale, F.; J. Biomed. Mater. Res., Part A 2014, 102, 4473.
8. Chen, Q.; Thouas, G. A.; Mater. Sci. Eng., $R$ 2015, 87, 1.

9. Torres, Y.; Sarria, P.; Gotor, F. J.; Gutiérrez, E.; Peon, E.; Beltrán, A. M.; González, J. E.; Surf. Coat. Technol. 2018, 348, 31.

10. Casagrande, R. B.; Kunst, S. R.; Beltrami, L. V. R.; Aguzzoli, C.; Brandalise, R. N.; Malfatti, C. F.; J. Coat. Technol. Res. 2018, 15, 1089.

11. Sanchez, C.; Julián, B.; Belleville, P.; Popall, M.; J. Mater. Chem. 2005, 15, 3559.

12. José, N. M.; Prado, L. A. S. A.; Quim. Nova 2005, 28, 281.

13. Sun, J.; Akdogan, E. K.; Klein, L. C.; Safari, A.; J. Non-Cryst. Solids 2007, 353, 2807.

14. Miyazaki, T.; Ohtsuki, C.; Kyomoto, M.; Tanihara, M.; Mori, A.; Kuramoto, K. I.; J. Biomed. Mater. Res., Part A 2003, 67, 1417.

15. Ravarian, R.; Zhong, X.; Barbeck, M.; Ghanaati, S.; Kirkpatrick, C. J.; Murphy, C. M.; Schindeler, A.; Chrzanowski, W.; Dehghani, F.; ACS Nano 2013, 7, 8469.

16. Sarmento, V. H. V.; Schiavetto, M. G.; Hammer, P.; Benedetti, A. V.; Fugivara, C. S.; Suegama, P. H.; Pulcinelli, S. H.; Santilli, C. V.; Surf. Coat. Technol. 2010, 204, 2689.

17. Suzana, A. F.; Ferreira, E. A.; Benedetti, A. V.; Carvalho, H. W. P.; Santilli, C. V.; Pulcinelli, S. H.; Surf. Coat. Technol. 2016, 299, 71.

18. ASTM F136-13: Standard Specification for Wrought Titanium6Aluminum-4Vanadium ELI (Extra Low Interstitial) Alloy for Surgical Implant Applications (UNS R56401); ASTM International, West Conshohocken, PA, 2013.

19. Kunst, S. R.; Cardoso, H. R. P.; Oliveira, C. T.; Santana, J. A.; Sarmento, V. H. V.; Muller, I. L.; Malfatti, C. F.; Appl. Surf. Sci. 2014, 298, 1.

20. Kros, A.; Jansen, J. A.; Holder, S. J.; Nolte, R. J. M.; Sommerdijk, N. A. J. M.; J. Adhes. Sci. Technol. 2002, 16, 143.

21. Santana, J. A.; Araujo, R. G. O.; de Jesus, F. A.; Lima, K. S.; Machado, G.; Cruz, M. C. P.; Sarmento, V. H. V.; J. Braz. Chem. Soc. 2018, 29, 782.

22. ASTM D3359-17: Standard Test Methods for Rating Adhesion by Tape Test; ASTM International, West Conshohocken, PA, 2017.

23. Schneider, C. A.; Rasband, W. S.; Eliceiri, K. W.; Nat. Methods 2012, 9, 671.

24. Kokubo, T.; Takadama, H.; Biomaterials 2006, 27, 2907.

25. Kunst, S. R.; Beltrami, L. V. R.; Boniatti, R.; Quevedo, M. C.; Bastos, A. C.; Oliveira, C. T.; Ferreira, M.; Menezes, T. L.; Malfatti, C. F.; Mater. Res. 2017, 20, 1735.

26. Carvalho, H. W. P.; Santilli, C. V.; Briois, V.; Pulcinelli, S. H.; RSC Adv. 2013, 3, 22830.

27. Carvalho, H. W. P.; Suzana, A. F.; Santilli, C. V.; Pulcinelli, S. H.; Polym. Degrad. Stab. 2014, 104, 112.

28. de Jesus, F. A.; Santos, S. T. S.; Caiut, J. M. A.; Sarmento, V. H. V.; J. Lumin. 2016, 170, 588.

29. Carvalho, H. W. P.; Suzana, A. F.; Santilli, C. V.; Pulcinelli, S. H.; Polym. Eng. Sci. 2013, 53, 1253. 
30. Kashiwagi, T.; Hirata, T.; Brown, J. E.; Macromolecules $\mathbf{1 9 8 5}$ $18,131$.

31. Kashiwagi, T.; Morgan, A. B.; Antonucci, J. M.; VanLandingham, M. R.; Harris, R. H.; Awad, W. H.; Shields, J. R.; J. Appl. Polym. Sci. 2003, 89, 2072.

32. Li, J.; Liu, X. In Surface Coating and Modification of Metallic Biomaterials; Woodhead Publishing: Shanghai, 2015, p. 159-183.

33. Rodrigues, A. V.; Oliveira, N. T. C.; dos Santos, M. L.; Guastaldi, A. C.; J. Mater. Sci.: Mater. Med. 2015, 26, 1.

34. Salvador, D. G.; Marcolin, P.; Beltrami, L. V. R.; J. Appl. Polym. Sci. 2017, 134, 45470.

35. Souza, J. C. M.; Barbosa, S. L.; Ariza, E. A.; Henriques, M.; Teughels, W.; Ponthiaux, P.; Celis, J. P.; Rocha, L. A.; Mater. Sci. Eng., C 2015, 47, 384.

36. Deflorian, F.; Rossi, S.; Fedrizzi, L.; Electrochim. Acta 2006, $51,6097$.

37. Zheng, S.; Li, J.; J. Sol-Gel Sci. Technol. 2010, 54, 174.

38. Kunst, S. R.; Oliveira, C. T.; Inácio, C.; Victor, H. V.; Int. J. Electrochem. Sci. 2013, 8, 3.

39. García, C.; Ceré, S.; Durán, A.; J. Non-Cryst. Solids 2006, 352, 3488.

40. Coan, T.; Barroso, G. S.; Machado, R. A. F.; de Souza, F. S.; Spinelli, A.; Motz, G.; Prog. Org. Coat. 2015, 89, 220.

41. Amouzou, D.; Fourdrinier, L.; Maseri, F.; Sporken, R.; Appl. Surf. Sci. 2014, 320, 519.

42. Gama, R. O.; Bretas, R. E. S.; Oréfice, R. L.; Adv. Polym. Technol. 2018, 37, 654.

43. van Ooij, W. J.; Zhu, D.; Stacy, M.; Seth, A.; Mugada, T.; Gandhi, J.; Puomi, P.; Tsinghua Sci. Technol. 2005, 10, 639.
44. Flis, J.; Kanoza, M.; Electrochim. Acta 2006, 51, 2338.

45. Tylkowski, B.; Tsibranska, I.; J. Chem. Technol. Metall. 2015, $50,3$.

46. Chung, J. J.; Sum, B. S. T.; Li, S.; Stevens, M. M.; Georgiou, T. K.; Jones, J. R.; Macromol. Rapid Commun. 2017, 38, 1700168.

47. Ribeiro Filho, S. L. M.; Lauro, C. H.; Bueno, A. H. S.; Brandão, L. C.; Measurement 2016, 88, 223.

48. Zhang, Z.; Ge, B.; Men, X.; Li, Y.; Colloids Surf., A 2016, 490, 182.

49. Wieland, M.; Chehroudi, B.; Textor, M.; Brunette, D. M.; J. Biomed. Mater. Res. 2002, 60, 434.

50. Kunzler, T. P.; Drobek, T.; Schuler, M.; Spencer, N. D.; Biomaterials 2007, 28, 2175.

51. Yan, Y.; Chibowski, E.; Szcześ, A.; Mater. Sci. Eng., C 2017, 70, 207.

52. Ribeiro, D. V.; Souza, C. A. C.; Abrantes, J. C. C.; Rev. IBRACON Estrut. Mater. 2015, 8, 529.

53. Kumar, S.; Sankara Narayanan, T. S. N.; Saravana Kumar, S.; Corros. Sci. 2010, 52, 1721.

54. Heakal, F. E.; Ghoneim, A. A.; Mogoda, A. S.; Awad, K.; Corros. Sci. 2011, 53, 2728.

55. Tedim, J.; Bastos, A. C.; Kallip, S.; Zheludkevich, M. L.; Ferreira, M. G. S.; Electrochim. Acta 2016, 210, 215.

56. Coelho, L. B.; Mouanga, M.; Druart, M.; Recloux, I.; Cossement, D.; Olivier, M.; Eval. Program Plann. 2016, 110, 143.

Submitted: May 21, 2019

Published online: August 20, 2019 